\title{
Evaluation of Factors Influencing Diabetes Management Among Pregnant Women in Ahiazu Mbaise, Imo State
}

\author{
Nwaokoro J. C. ${ }^{1,}{ }^{\text {* }}$, Onwuliri V. A. ${ }^{2}$, Emerole C. O. ${ }^{1}$, Ibe S. N. O. ${ }^{1}$, Nwadike P. O. ${ }^{3}$, Nwufo R. C. ${ }^{1}$, \\ Ebiriekwe S. C. ${ }^{4}$
}

${ }^{1}$ Department of Public Health Technology, Federal University of Technology, Owerri, Nigeria

${ }^{2}$ Department of Biochemistry, Federal University of Technology, Owerri, Nigeria

${ }^{3} \mathrm{KNCV}$ Nigeria/ Challenge TB Project, Abuja, Nigeria

${ }^{4}$ Raw Materials Research and Development Council (RMRDC), Abuja, Nigeria

\section{Email address:}

nwaokorojc@yahoo.com (Nwaokoro, J. C.), violadaku@yahoo.com (Onwuliri, V. A.), coemerole@yahoo.com (Emerole, C. O.), sallyibe@yahoo.com (Ibe S. N. O.), chinyerenwufo@yahoo.com (Nwufo R. C.), petrousbone@yahoo.com (Nwadike P. O.), sabhermis@yahoo.com (Ebiriekwe S. C.)

\section{To cite this article:}

Nwaokoro J. C., Onwuliri V. A., Emerole C. O., Ibe S. N. O., Nwadike P. O., Nwufo R. C., Ebiriekwe S. C.. Evaluation of Factors Influencing Diabetes Management Among Pregnant Women in Ahiazu Mbaise, Imo State. Science Journal of Public Health. Special Issue: Who Is Afraid of the Microbes. Vol. 3, No. 5-1, 2015, pp. 51-57. doi: 10.11648/j.sjph.s.2015030501.20

\begin{abstract}
Diabetes mellitus is a group of metabolic diseases characterized by elevated blood glucose level (hyperglycaemia) resulting from defects in insulin secretion, insulin action or both. Many pregnant women are at the risk of developing diabetes, however most may be unassuming. This study therefore, sought to determine the level of knowledge of diabetes management among pregnant women in Ahiazu, Mbaise. The study employed a descriptive study design to ascertain the level of knowledge of pregnant women in Ahiazu, Mbaise on the management of diabetes. A total of 220 respondents were assessed with the use of questionnaire between April and October, 2014 at Ahiazu, Mbaise L.G.A. The collected data were analyzed with descriptive statistics using the computer software called Statistical Package for Social Science (SPSS). Results revealed the knowledge level to be higher (54.5\%) among pregnant women at the age range of 31-35 years. The educational status was seen to be higher (49.5\%) among respondents in secondary level of education. Those with high blood pressure were $59.1 \%$ and those who have trace of family history of diabetes were found to be $76.4 \%$. Generally, study subjects had good understanding of the factors that influence the management of diabetes. However, there should be more health education for people in the study area and beyond on the management of diabetes in order to reduce the mortality and morbidity rate of diabetes diseases.
\end{abstract}

Keywords: Diabetes, Management, Pregnancy, Women

\section{Introduction}

Diabetes mellitus is a group of metabolic diseases characterized by elevated blood glucose levels (hyperglycemia) resulting from defects in insulin secretion, insulin action or both [1, 2, 3]. Insulin is a hormone manufactured by the beta cells of the pancreas, which is required to utilize glucose from digested food as an energy source and helps to regulate blood sugar [2] Chronic hyperglycemia is associated with micro-vascular and macrovascular complications that can lead to visual impairment, blindness, kidney disease, nerve damage, amputations, heart disease, and stroke. In 1997 an estimated 4.5\% of the US population had diabetes. Direct and indirect health care expenses were estimated at $\$ 98$ billion [3].

Diabetes is one of the serious health problems in the world and contributes directly or indirectly to thousands of death annually worldwide. Diabetes is an important public health challenge, it is a global non-communicable chronic disease and is largely asymptomatic, a person experiences very few signs and symptoms until damage occurs to a target organ [4]. In a lay man's view, diabetes is termed as 'sugar ailment'. This simply means is a condition in which the body cannot change sugars and starches (carbohydrates) into energy. This happens when the body cannot make enough insulin or cannot use the insulin it makes. As a result, extra sugar in the blood can lead to damage in the blood vessels, eyes, kidneys, heart, and nerves [5]. Diabetes in pregnancy 
creates a double burden and challenge to the pregnant woman.

Pregnancy and child birth are special events in women's lives, and, indeed, in the lives of their families. This can be a time of great hope and joyful anticipation. Although pregnancy is not a disease but a normal physiological process that is associated with certain risks to health and survival both for the woman and for the newborn she delivers [6]. Gestational diabetes mellitus is a high blood sugar condition that some women get during pregnancy which usually goes away after the delivery. Although, care must be taken to avoid having type 2 diabetes in the long run.

In a woman with pre-existing diabetes (which includes type 1 and type 2), blood sugar that remains high can trigger or worsen certain health problems which may include High Blood Pressure, Preeclampsia, Kidney disease, Nerve damage, Heart disease, Blindness. A woman with preexisting diabetes whose blood sugar remains high has an increased chance of having Miscarriage, Preterm birth, Stillbirth, Caesarean section etc. [7].

Blood sugar that remains high in a woman with gestational diabetes can cause her baby to grow very large (about 9 pounds or more). Being very large makes it hard for the baby to be born through the birth canal and can cause nerve damage to the baby's shoulder during birth [8]. A very large baby has an increased chance of being overweight or obese later in life. Being overweight or obese increases the chances of also having diabetes later in life [9].

Blood sugar that remains high in a pregnant woman with type 1 or type 2 diabetes can cause her baby to have health problems like birth defects (especially of the brain, spine, and heart), increased birth weight, nerve damage to the shoulder during delivery, low blood sugar after birth, increased chance of overweight, obesity, and/or diabetes later in life [8].

Gestational diabetes mellitus is associated with important prenatal and long term health risks and many of the risks increases in relation to the severity of maternal hyperglycaemia. Women with impaired glucose tolerance in the early pregnancy are at high risk for type 2 diabetes [10]. Optimal medical care has to be provided to avoid short and long term sequelae for the fetus and the mothers.

Gestational diabetes mellitus is one of the most common complications in pregnancy. Ethnic group investigated, seems to be a factor on $3 \%$ to $14 \%$ of the pregnant women affected [10]. Actual estimations suggest that the prevalence of GDM will significantly increase in the near future due to the rising rate of obesity and glucose intolerance in young women in business driven state like Imo state [10].

\subsection{Socioeconomic Status / Education of the Women}

Considering socioeconomic levels, Innes et al., [8], did not find an association between gestational diabetes mellitus development and private or public insurance, occupation during pregnancy, or education of the parents of the pregnant woman at the time of her birth. However, they found an inverse association between the educational level of the pregnant woman and gestational diabetes mellitus, after adjustment for other social, economic and demographic factors [8]. Berkowitz et al., [11] conducted a study on a hospital sample composed of all socioeconomic categories, and found greater prevalence of gestational diabetes mellitus among women in a public health service, compared with those coming from private clinics [11]. A study carried out in Italy found that high levels of maternal education were associated with reduced risks of gestational diabetes mellitus (OR: 0.61 ; 95\%CI: 0.4-0.9), compared to less educated women. When categorized by occupation, non-employed women with a primary level of education presented an OR of 1.87 (95\% CI: 1.1-3.2) and the blue-collar workers, an OR of 1.73 (95\%CI: 1.1-2.9), compared to white-collar women, even after controlling for age, BMI, height, family history of diabetes mellitus and previous pregnancy [12]. On the other hand, Yang et al., [13] when studying Chinese pregnant women, did not find an association between gestational diabetes mellitus and education or average household income [13]. Keshavarz's study on pregnant Iranian women, did not find an association between gestational diabetes mellitus and education or occupation; however, they found an association with low socioeconomic level. Both studies did not control for confounders [14].

An inverse association between socioeconomic status and type 2 diabetes mellitus was found in some studies carried out by Brancati et al., [15] and Robbins et al., [16]. Despite the fact that the epidemiologies of these two conditions are similar, it is not clear if the socioeconomic situation can be a risk factor for gestational diabetes mellitus. It is possible that the low maternal socioeconomic level is a proxy for the socioeconomic level of the parents, and the latter is potentially acting as a confounding factor for being born with low weight, short stature and greater weight in adulthood, characteristics that, in previous studies, had been detected as more frequent in poor populations and with smaller educational levels and described as independent factors of type 2 diabetes mellitus risk. Thus, a careful hierarchical analysis taking into account the income of the parents could elucidate the relationship between current socioeconomic factors and gestational diabetes mellitus [17].

\subsection{Cigarette Smoking}

Although cigarette smoking is positively associated with hyperinsulinism and insulin resistance in some studies [18, 19] the association between tobacco and gestational diabetes mellitus has been little investigated. A cross-sectional study carried out in Scandinavia showed that to smoke more than ten cigarettes per day during pregnancy affects the homeostasis of the glucose towards gestational diabetes mellitus [20]. Researchers have shown that an increased risk for gestational diabetes mellitus was found among smokers compared to non smokers $[9,21,22]$.

\subsection{Parity}

The study by [23] after controlling for age, found women with two, three and four or more childbirths, more disposed 
to diabetes than those with only one child birth. This has been corroborated [11, 14, 25, 26, 27], after controlling for age, pre-pregnancy BMI, height, family history of diabetes mellitus and weight gain during pregnancy. Kumari's study on grand multi parity, in a uniformly high socioeconomic population (United Arab Emirates), found that women with parity greater than ten had greater gestational diabetes mellitus incidence. When stratified by age, these pregnant women belonged to the oldest category [24].

The association between parity and diabetes is strongly linked to obesity and age. Women with higher parity frequently are older and more obese. However, age is a potential confounder in the association between parity and gestational diabetes mellitus.

To successfully manage diabetes, a pregnant woman needs to understand how food and nutrition affect the body. Preventive strategies such as reducing consumption of alcohol and avoidance of tobacco intake, reduction of blood cholesterol level, implementation of a dietary routine as prescribed by a dietician and avoidance of sedentary lifestyle as well as medical treatment with appropriate drugs.

The problem of diabetes remains an area of public health focus all over the world. It contributes to the major cause of hospital admission in every health care establishment. Diabetes once diagnosed in a family, it automatically leads to economic loss to the family. A rapid increase in diabetes cases causes a direct increase in the mortality and morbidity rate in the society.

Due to lack of knowledge on the factors that contributes to the development of diabetes, many people stand the risk of getting the disease. Due to loss of resources and human lives that this disease cause in the society there is need to research more in the risk factors of diabetes among pregnant women in Ahiazu Mbaise L.G.A and beyond.

The general objective of this study was to determine the factors influencing diabetes management among pregnant women in Ahiazu Mbaise. These objectives include;

- To determine the level of knowledge of diabetes management among pregnant women in Ahiazu Mbaise and beyond.

- To ascertain the attitude of pregnant women on dietary intake for the management of diabetes.

- To establish the impact of socio-demographic factors as a risk associated with the occurrence of diabetes among pregnant women in Ahiazu Mbaise.

\section{Methodology}

\subsection{Research Design}

This study involved the use of survey method to establish systematic relationship or association between risk factors and gestational diabetes mellitus.

\subsection{Area of Study}

Ahiazu Mbaise Local Government Area of Imo State, Southeastern, Nigeria was used as study area. The high level of farming and commercial activities in the area attracts people from different parts of south eastern Nigeria. National census conducted in 2006 has it that the population is 170 , 902 covering a total area of 114 square kilometers approximately.

\subsection{Target Population}

The target population of this study comprised pregnant women attending ante-natal clinics in health care centres, such primary health centres in Ahiazu Local Government Council.

\subsection{Ethical Consideration}

The study was approved by the ethical committee of the hospitals and informed consent was also obtained from the subjects prior to administering the questionnaires. Good interpersonal relationship was maintained.

\subsection{Sampling and Sampling Technique}

The sample size formula by Leslie for cross-sectional studies was used in calculating and determining the sample size needed to be representative of the given population and is given as:

$$
N=\frac{Z^{2} Q(1-P)}{d^{2}}
$$

where; $Z=$ score corresponding $95 \%$ confidence interval= 1.96 ,

$\mathrm{P}=$ the study assumed population proportion of $15 \%$ since this would provide the maximum sample size.

$$
\begin{aligned}
& P=15 \% \\
& Q=1-P \\
& d=\text { precision }(+/- \text { of } 5 \%)
\end{aligned}
$$

The sample size of 230 was used to generally represent the population of the study area to avoid error of data collection however, 220 questionnaires were filled and returned. This was finally used as the sample size.

Random sampling technique was employed, on the basis that only women who attended antenatal care clinics were interviewed with the designed questionnaire at the health care centre premises, questionnaires were filled and returned on the spot. Seventeen (23) diabetic women were interviewed each day through ballot process for period of 10 days at healthcare centers.

\subsection{Instrument Used for Data Collection}

A structured questionnaire including a set of detailed predetermined questions was developed for the collection of relevant data for this study. Questionnaire items had choice questions by which subjects were directed to select a response option that most nearly describe their position.

\subsection{Validity/Reliability of Instruments}

The validity of the study instrument is said to be authentic considering the fact that it was first given a peer review by 
authors, necessary suggestions, inputs and corrections were also made. It was then presented to professionals in the area of study for more vetting and finally approved on the basis that the contents were clear enough and in line with the study objectives and research questions.

\subsection{Method of Data Collection}

The copies of the questionnaire were administered randomly to diabetic ante-natal women in the health facilities at Ahiazu Mbaise L.G.A. For effective administration of the questionnaires, some staff of the hospital was used as research assistants in distribution and supervision. Completed questionnaires were checked and collected the same to minimize error of random sample.

The content of the questionnaire was disclosed before the respondents and their consents were obtained before administering the questionnaire. Only consenting volunteerss were recruited as resspondents those who refused were skipped.

\subsection{Method of Data Analysis}

The data collected were coded and entered into computer software, statistically analyzed using Statistical Package for Social Science (SPSS) Version 20.0. The results were presented in frequency and simple percentages. The statistical relationship between factors that influence diabetes management in Ahiazu Mbaise were tested with chi square at $\mathrm{P} \leq 0.05$.

\section{Results}

The results obtained in this study showed that factors which influence diabetes management among pregnant women in Ahiazu Mbaise LGA, Imo State are varied (Table 1). The mean age of $36.0 \pm 1.02$ years was observed among the respondents who were all diabetic. This may be the prevalent age range of pregnant women in the area or possibly the age range at which diabetes is prevalent. Results of demographic factors are shown in Table 1 below. The multivariate analysis of socio-demographic characteristics of effect of diabetes on factors affecting pregnant women is also shown in Table 1.

Table 1. Socio-Demographic data of respondents.

\begin{tabular}{lll}
\hline Variables & Frequency $\mathbf{( N = 2 2 0 )}$ & Percentage (\%) \\
\hline Age Range & & \\
25-30 years & 30 & 13.6 \\
31-35 years & 120 & 54.5 \\
36-40 years & 25 & 11.4 \\
41-45 years & 31 & 14.1 \\
46-50 years & 9 & 4.1 \\
$\geq 50$ years & 5 & 2.3 \\
Educational level & & \\
Primary education & 70 & 31.8 \\
Secondary education & 109 & 49.5 \\
Tertiary education & 39 & 17.7 \\
No education & 2 & 0.9 \\
\hline
\end{tabular}

\begin{tabular}{lll}
\hline Variables & Frequency $(\mathbf{N}=\mathbf{2 2 0})$ & Percentage (\%) \\
\hline Occupational status & & \\
Trading & 101 & 45.9 \\
Civil servants & 55 & 25.0 \\
Farming & 35 & 15.9 \\
Student & 20 & 9.1 \\
Artisan & 9 & 4.1 \\
Religion of preference & & \\
Christian & 160 & 72.7 \\
Muslim & 20 & 9.1 \\
No religion & 40 & 18.2 \\
\hline
\end{tabular}

Table 2. Knowledge of diabetes occurrence among pregnant women.

\begin{tabular}{|c|c|c|}
\hline Variables & Frequency $(\mathrm{N}=\mathbf{2 2 0})$ & Percentage $(\%)$ \\
\hline \multicolumn{3}{|c|}{ Family history of diabetes } \\
\hline Yes & 168 & 76.4 \\
\hline No & 52 & 23.6 \\
\hline \multicolumn{3}{|c|}{ Relationship with the family member who is diabetic } \\
\hline Mother & 40 & 18.2 \\
\hline Sister & 30 & 13.6 \\
\hline Others & 150 & 68.2 \\
\hline \multicolumn{3}{|c|}{ Type of diabetes the patient has } \\
\hline Type 1 & 20 & 9.1 \\
\hline Type 2 & 120 & 54.5 \\
\hline GDM & 80 & 36.4 \\
\hline \multicolumn{3}{|c|}{ Diagnosed and confirmed of GDM } \\
\hline Yes & 80 & 36.4 \\
\hline No & 140 & 63.6 \\
\hline \multicolumn{3}{|c|}{ Period the patient diagnosed of GDM } \\
\hline 3 months ago & 10 & 4.5 \\
\hline 6 months & 130 & 59.1 \\
\hline 1 year & 40 & 18.2 \\
\hline $2-4$ years & 30 & 13.6 \\
\hline$\geq 5$ years & 10 & 4.5 \\
\hline
\end{tabular}

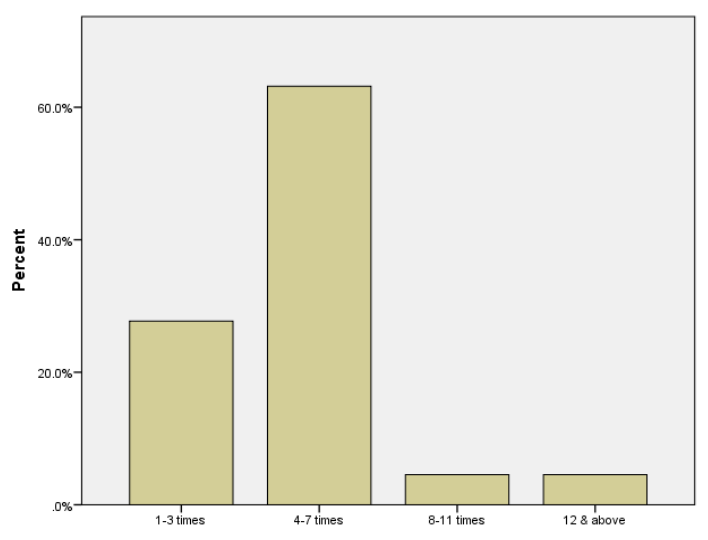

Figure 1. Parity of study subjects.

Table 2 indicated the knowledge of diabetes occurrence among pregnant women. The relationship of diabetes with family members was highest in others $(68.2 \%)$ compared mother, sister or brother with $18.2 \%$ and (13.6\%). During the development of the questionnaire, it became clear that many people with diabetes are unsure as to whether they have Type 1 or Type 2 ; therefore, the questionnaire included three questions to help ascertain probable diabetes type (Table 2). 
For parity (i.e. the number pregnancies). Highest parity range was between 4-7 times. Those who had carried pregnancies 8-11 times and 12 times were few $(4.5 \%)$ as shown in Figure 1.

Table 3. Knowledge of Factors influencing management of diabetes.

\begin{tabular}{|c|c|c|}
\hline Variables & Frequency $(\mathrm{N}=\mathbf{2 2 0})$ & Percentage (\%) \\
\hline \multicolumn{3}{|c|}{$\begin{array}{l}\text { Aware that physical exercise plays an important role in diabetes } \\
\text { management }\end{array}$} \\
\hline Yes & 140 & 63.6 \\
\hline No & 80 & 36.4 \\
\hline \multicolumn{3}{|c|}{ Have high blood pressure } \\
\hline Yes & 130 & 59.1 \\
\hline No & 90 & 40.9 \\
\hline \multicolumn{3}{|c|}{ Presence of a smoker in the family } \\
\hline Yes & 52 & 23.6 \\
\hline No & 168 & 76.4 \\
\hline \multicolumn{3}{|c|}{ For how long the smoker lasted in smoking habit } \\
\hline 2-6 months & 160 & 72.7 \\
\hline 7-11 months & 40 & 18.2 \\
\hline 1 year & 15 & 6.8 \\
\hline$>1$ year & 5 & 2.3 \\
\hline \multicolumn{3}{|c|}{ Alcohol consumption of the mother } \\
\hline Yes & 40 & 18.2 \\
\hline No & 180 & 81.8 \\
\hline \multicolumn{3}{|c|}{ Observed medical check up / treatment } \\
\hline Yes & 114 & 51.8 \\
\hline No & 106 & 48.2 \\
\hline
\end{tabular}

Table 4 below, presents the influence of nutrition on management of diabetes. Figure 2, shows the level of presentation for and adherence to diabetes health educator's encouragement on type of food intake.

Table 4. Nutritional influence on management of diabetes.

\begin{tabular}{|c|c|c|}
\hline Variables & Frequency $(\mathrm{N}=\mathbf{2 2 0})$ & Percentage (\%) \\
\hline \multicolumn{3}{|c|}{ Aware of daily nutritional recommendations } \\
\hline Yes & 158 & 71.8 \\
\hline No & 62 & 28.2 \\
\hline \multicolumn{3}{|c|}{ Any special diet for management of diabetes } \\
\hline Yes & 165 & 75.0 \\
\hline No & 55 & 25.0 \\
\hline \multicolumn{3}{|c|}{ Type of food preference by the diabetes patient } \\
\hline Carbohydrates & 30 & 13.6 \\
\hline Fruit & 50 & 22.7 \\
\hline Milk & 40 & 18.2 \\
\hline Vegetable & 40 & 18.2 \\
\hline Protein & 60 & 27.3 \\
\hline \multicolumn{3}{|c|}{$\begin{array}{l}\text { Financial constraint as a factor that affects schedule with doctors for } \\
\text { diabetes check up }\end{array}$} \\
\hline Yes & 140 & 63.6 \\
\hline No & 80 & 36.4 \\
\hline \multicolumn{3}{|c|}{$\begin{array}{l}\text { Received any kind of help from community/government concerning } \\
\text { diabetes condition }\end{array}$} \\
\hline Yes & 110 & 50.0 \\
\hline No & 110 & 50.0 \\
\hline
\end{tabular}

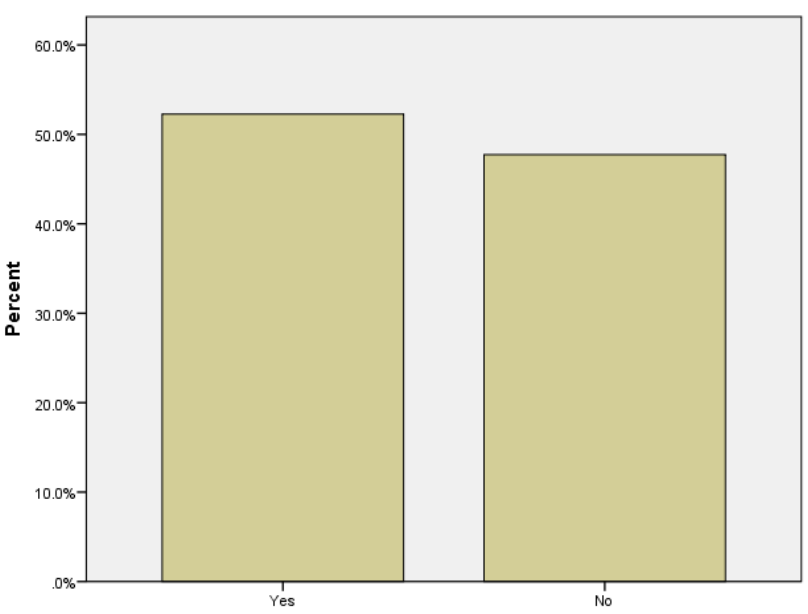

Figure 2. Adherence to Diabetes health educator's counselling on type of food intake.

Chi- square test of some factors influencing diabetes management is shown in Tables 5 and 6 below:

Table 5. Influence of education in management of diabetes.

\begin{tabular}{llll}
\hline Educational level & Yes & No & Total \\
\hline Primary education & 40 & 30 & 70 \\
Secondary education & 91 & 18 & 109 \\
Tertiary education & 20 & 19 & 39 \\
None education & 1 & 1 & 2 \\
Total & $\mathbf{1 5 1}$ & $\mathbf{6 8}$ & $\mathbf{2 2 0}$ \\
\hline
\end{tabular}

$\chi^{2}=21.7$, degree of frequency $(\mathrm{df})=3$. Critical value of 8 at 0.05 level of significance, $\chi^{2}=21.7>$ Critical value 8

The difference is statistically significant; the calculated $\chi^{2}$ value is 21.7 and is greater than the critical value. Therefore, education is associated with proper management of diabetes in Ahiazu Mbaise.

Table 6. Influence of type of food intake in management of diabetes.

\begin{tabular}{llll}
\hline Type of food intake & Preferred food & Not preferred food & Total \\
\hline Carbohydrate & 20 & 10 & 30 \\
Fruits & 35 & 15 & 50 \\
Milk & 20 & 20 & 40 \\
Vegetable & 35 & 5 & 40 \\
Protein & 50 & 10 & 60 \\
& 160 & 60 & 220 \\
\hline
\end{tabular}

$\chi 2=11.82, \mathrm{DF}=4$. Critical value of 9.5 at P-value 0.05 level of significance

$\chi 2=11.82>$ Critical value 9.5

The difference is statistically significant; the calculated $\chi^{2}$ value is 11.82 and is greater than the critical value. Therefore, type of food intake influences management of diabetes in Ahaizu Mbaise.

\section{Discussions}

From the findings of the study it was revealed that the pregnant women in Ahiazu Mbaise have a good knowledge 
about management of diabetes. Among the pregnant women interviewed, type 2 diabetes were higher in older population than others. This corroborates with the fact that diabetes goes with age $[11,26]$. However, it is becoming more common for all child bearing aged women to develop type 2 diabetes [9].

The findings were incongruent with that of Nwaokoro et al [9], who noted that among all patients suffering from diabetes, type 2 diabetes has about $90 \%$ of such cases when compared with result of this study that has $54 \%$. The control of type 2 diabetes requires dietary manipulation, use of oral hypoglycemia. Most patients acquire this diseases after 40 years because it is associated with age increase, it may also occur in younger ones [28]. The subjects have good understanding of diabetes management, it is not surprising because, they have health care workers who are trained on the management of diabetes around them.

Awareness of special diet for the management of diabetes among the subjects was remarkable. Protein intake preference had the highest value. Thus, the recommendation of [28], that more high calories intake should be avoided since it is commonly associated with type 2 diabetes seems to be well taken at Ahiazu Mbaise.

With respect to the management of diabetes on those who have high blood pressure, the result indicated that high blood pressure is the major factor affecting the management of diabetes. Thus, it is important to create more awareness on the management of blood pressure among people with diabetes and to reduce it as a confounding factor. The high number of subjects with increased blood pressure could be due to the fact that most of the patients did not understand they have high blood pressure, as most hardly go for blood pressure check. Smoking was revealed to have significant influence on the management of diabetes.

It was also observed that the study subjects hardly went for medical checkup to see if there is any other case of diseases. Those involved in trading were more in number than those with other occupations; most of the traders were also found to have lower levels of educational background. Therefore, this is consistent with the observation that those with secondary education have higher percentage of diabetes compared to tertiary educated counterparts.

The women aged 31-35 years had the highest percentage of type 2 diabetes compared to others. It could be that, 31-35 years did not adhere much to the instruction given to them by the health educators. More of the respondents were Christians when compared to other religion in Ahiazu Mbaise, which could be that other tribes that belong to different religion were either not living there or did not use the health centres.

Financial constraint is a factor that affects schedule with doctors for diabetes checkup, $140(63.6 \%)$ said yes while those who said no were $80(36.4 \%)$. It also seem that the community / government help the patients in managing their diabetes condition viz help with nutritional food when compared to provision of insulin and provision of money. It is noted that this could be as a result of Non - Governmental Organizations (NGOs) such as Hammer Home the Glucose
(HHG) and Professor Onwuliri Foundation (PROFOUND) which are in partnership with the local government rendering charity, with provision of nutritional food, oral hypoglycaemic agents and insulin thereby reducing spending and subsequently improves their health.

Generally, most of the diabetic pregnant women had family history of diabetes but were not aware of it, due to lack of good medical checkup.

\section{Conclusion}

From the foregoing, it is obvious that the people of Ahiazu Mbaise are aware of the menace of diabetes and the factors influencing its management.

In view of the ongoing, the following recommendations are hereby made:

1. To reduce the rate of diabetes among pregnant women Ahiazu Mbaise, Imo State through awareness by organizing health programs for pregnant women, publishing journals on diabetes risk factors.

2. By educating the pregnant women on nutritional diet and life style, like taking proteins and vegetables as nutritional diet to reduce mortality and morbidity of diabetes diseases.

3. The pregnant women should be involved in physical exercise which is very encouraging as part of the prevention and management in the field of diabetes.

4. The pregnant women should be advised to visit any healthcare centres for medical checkup which also contribute to the prevention and management of diabetes.

These recommendations if put in place, can foster more ideas and improve knowledge of people especially pregnant women in Ahiazu Mbaise and beyond on the risk factors influencing diabetes management among pregnant women and how to avoid them.

\section{References}

[1] P.O. Emeharole, "Communicable and Non-Communicable Diseases," Control Technology, 2008, PP. 162-178.

[2] A.L. Grabber, T.A. Elasy, D. Quinn and K. Wolff, "Improving glycemic control in adults with diabetes mellitus," South Med Journal, 2002, vol. 95: 684-690.

[3] American Diabetes Association, "Diagnosis and Classification of Diabetes Mellitus," Diabetes Care. Jan. 2010, 33(Suppl 1): S62-S69, doi: 10.2337/dc10-S062, PMCID: PMC2797383

[4] R.F. Hamman, R.R. Wing, S.L. Edelstein M. J. Lachin, George A. Bray, Linda Delahanty, Mary Hoskin, Andrea M. Kriska, Elizabeth J. Mayer-Davis, Xavier Pi-Sunyer, Judith Regensteiner, Beth Venditti, and Judith Wylie-Rosett, "Effect of weight loss with lifestyle intervention on risk of diabetes," Diabetes Care 2006;29:2102-2107.

[5] H. King, R.E. Aubert and W.H. Herman, "Global burden of diabetes, 1995-2025: prevalence, numerical estimates, and projection," Diabetes Care 1998, vol. 21:1414-1431. 
[6] World Health Organization, "Definition and diagnosis of diabetes mellitus and intermediate hyperglycemia: report of a WHO/IDF consultation. Geneva, 2006.

[7] Insulin Dependent Diabetes Trust, "Pregnancy and Gestational Diabetes,” Information Leaflet, January 2013.

[8] K.E. Innes, T.E. Byers, J.A. Marshall, A. Barón, M. Orleans and R.F. Hamman, "Association of a woman's own birth weight with subsequent risk for gestational diabetes," JAMA. 2002; 287:2534-2541, doi: 10.1371/journal.pone.0071392.

[9] J.C. Nwaokoro, A.O. Ede, C. Emerole, S. Ibe, A.N. Amadi, I.N.S. Dozie, S.C. Iwuji and A.A. Nwaokoro, "Study on the effect of smoking on Type 2 Diabetic Patients in Federal Medical Center Owerri, Southeastern Nigeria," Asian Journal of Medical Sciences, 2014, vol. 5(3):63-71

[10] G. Ross, "Gestational diabetes". Australian family physician, 2006, Vol. 35 (6): 392-396. PMID 16751853

[11] G.S. Berkowitz, R.H. Lapinski, R. Wein and D. Lee,"Race/ethnicity and other risk factors for gestational diabetes," Am J Epidemiol. 1992; 135:965-973.

[12] S. Bo, B. Marchisio, M. Volpiano, G. Menato and G. Pagano, "Maternal low birth weight and gestational hyperglycemia," Gynecol Endocrinol 2003; 17:133-6.

[13] X. Yang, B. Hsu-Hage, H. Zhang, C Zhang and Y. Zhang, "Women with impaired glucose tolerance during pregnancy have significantly poor pregnancy outcomes," Diabetes Care, $2002 ; 25: 1619-1624$.

[14] M. Keshavarz, N.W. Cheung, G.R. Babaee, H.K. Moghadam, M.E. Ajami and M. Shariati, "Gestational diabetes in Iran: incidence, risk factors and pregnancy outcomes," Diabetes Res Clin Pract., 2005; 69:279-286.

[15] F.L. Brancati, P.K. Whelton, L.H. Kuller, and M.J. Klag, "Diabetes mellitus, race, and socioeconomic status," A population-based study. Annals of Epidemiology, 1996; 6, 67

[16] J.M. Robbins, V. Vaccarino, H. Zhang, and S.V. Kasl, "Socioeconomic status and type 2 diabetes in African American and non-Hispanic white women and men: evidence from the Third National Health and Nutrition Examination Survey," Am J Public Health2001; 91:76-83.

[17] C.G. Victora, S.R. Huttly, S.C. Fuchs and M.T. Olinto, "The role of conceptual frameworks in epidemiological analysis: a hierarchical approach,”. Int J Epidemiol 1997; 26:224-7.
[18] I.J. Perry, S.G. Wannamethee, M.K. Walker, A.G. Thomson, P.H. Whincup and A.G. Shaper, "Prospective study of risk factors for development of non-insulin dependent diabetes in middle aged British men," BMJ. 1995; 310:560-4.

[19] L.A. Sargeant, K.T. Khaw, S. Bingham, N.E. Day, R.N Luben, S. Oakes, et al., "Cigarette smoking and glycaemia: the EPIC-Norfolk Study. European Prospective Investigation into Cancer," Int J Epidemiol. 2001; 30:547-54.

[20] B. Zaren, G. Lindmark, L. Wibell and I. Folling, "The effect of smoking on glucose homeostasis and fetal growth in pregnant women," Ups J Med Sci. 2000; 105:41-56.

[21] C.G. Solomon, W.C. Willett, V.J. Carey, J. Rich-Edwards, D.J. Hunter, G.A. Colditz, et al. A prospective study of pregravid determinants of gestational diabetes mellitus. JAMA 1997; 278:1078-83.

[22] I.J. England, R.J. Levine, C. Qian, L.M. Soule, E.F. Schisterman, K.F. Yu, et al., "Glucose tolerance and risk of gestational diabetes mellitus in nulliparous women who smoke during pregnancy,” Am J Epidemiol. 2004; 160:1205-13.

[23] G.M. Egeland, R. Skjaerven and L.M. Irgens, "Birth characteristics of women who develop gestational diabetes: population based study," BMJ 2000; 321:546-7.

[24] A.S. Kumari and P. Badrinath, "Extreme grandmultiparity: is it an obstetric risk factor?" Eur J Obstet Gynecol. Reprod Biol 2002; 101:22-5.

[25] H.C. Jang, H.K. Min, H.K. Lee, N.H. Cho and B.E. Metzger, "Short stature in Korean women: a contribution to the multifactorial predisposition to gestational diabetes mellitus," Diabetologia 1998; 41:778-83.

[26] G. Di Cianni, L. Volpe, C. Lencioni, R. Miccoli, I. Cuccuru, A. Ghio, et al., "Prevalence and risk factors for gestational diabetes assessed by universal screening," Diabetes Res Clin Pract 2003; 62:131-7.

[27] F.F. Lauszus, J. Paludan and J.G. Klebe "Birthweight in women with potential gestational diabetes mellitus: an effect of obesity rather than glucose intolerance?" Acta Obstet Gynecol Scand., 1999; 78:520-5.

[28] International Diabetes Federation, Diabetes Atlas. 3rd edn. Brussels: International Diabetes Federation, 2006. 